\title{
LORENTZ SPACES FOR DECREASING REARRANGEMENTS OF FUNCTIONS ON TREES
}

\author{
JOSEP L. GARCIA-DOMINGO AND JAVIER SORIA
}

Abstract. We characterize the existence of a norm in the Lorentz spaces defined on trees, for non-linear decreasing rearrangements, as well as other functional properties (quasinormability, relationship with rearrangement invariant spaces, etc.). The main tool is the characterization of the saturation in Hardy-Littlewood's inequality for linearly decreasing functions.

Mathematics subject classification (2000): 05C05, 46E30, 46B25.

Key words and phrases: homogeneous trees, decreasing rearrangements, Lorentz spaces.

\section{REFERENCES}

[BS] C. Bennett And R. Sharpley, Interpolation of Operators, Pure and Applied Mathematics 129, Academic Press, 1988.

[CFPR] A. Cantón, J. L. Fernández, D. Pestana And J. M. Rodríguez, On harmonic functions on trees, Potential Anal. 15 (2001), 199-244.

[CRS] M. J. CARRO, J. A. RAPOSO AND J. SORIA, Recent Developments in the Theory of Lorentz Spaces and Weighted Inequalities, bookmanuscript 2003, submitted.

[CS] M. J. CARRO AND J. SORIA, Weighted Lorentz spaces and the Hardy operator, J. Funct. Anal. 112 (1993), 480-494.

[C] P. CARTIER, Fonctions harmoniques sur un arbre, Symp. Math. 9 (1972), 203-270.

[EHL] W. D. EVANS, D. J. HARRIS AND J. LANG, The approximation numbers of Hardy-type operators on trees, Proc. London Math. Soc. 83 (2001), 390-418.

[FTN] A. FigÀ-TAlamanca AND C. NebBia, Harmonic Analysis and Representation Theory for Groups Acting on Homogeneous Trees, Lecture Note Series 162, Cambridge University Press, 1991.

[GS] J. L. GARCIA-DOMINGO AND J. SORIA, A decreasing rearrangement for functions on homogeneous trees, to appear in European Journal of Combinatorics, (available at http://www.mat.ub.es / soria/Combinatoria.pdf)

[L] J. LEYDOLD, A Faber-Krahn type inequality for regular trees, Geom. Funct. Anal. 7 (1997), 364-378.

[LL] E. H. Lieb AND M. Loss, Analysis, Graduate Studies in Mathematics 14, American Mathematical Society, Providence, RI, 2001.

[Lo] G. G. LORENTZ, On the theory of spaces $\Lambda$, Pacific J. Math 1 (1951), 411-429.

[NS] K. NAIMARK AND M. SOLOMYAK, Eigenvalue estimates for the weighted Laplacian on metric trees, Proc. London Math. Soc. 80 (2000), 690-724.

[Pr1] A. R. PRUSS, Discrete convolution-rearrangement inequalities and the Faber-Krahn inequality on regular trees, Duke Math. J. 91 (1998), 463-514.

[Pr2] A. R. PRUSS, Discrete harmonic measure, Green's functions and symmetrization: a unified probabilistic approach, Ann. Univ. Mariae Curie-Sklodowska 55 (2001), 139-174.

[R] J. A. RAposo, Acotación de Operadores Maximales en Análisis Armónico, Ph. D. Thesis, Universitat de Barcelona, 1998. 